\title{
Quantitative RT-PCR on CYP1A1 Hetero- geneous Nuclear RNA: A Surrogate for the In Vitro Transcription Run-On Assay
}

\section{Cornelis J. Elferink and John} J. Reiners, Jr.

Wayne State University, Detroit, MI, USA

\section{ABSTRACT}

A quantitative reverse transcription polymerase chain reaction ( $R T-P C R)$ assay was developed to amplify a region of the CYPIA1 heterogeneous nuclear RNA ( hnRNA) transcript encompassing the first intron-exon boundary. The RT-PCR protocol uses a CYPIAl recombinant $R N A$ internal standard identical to the target hnRNA except for an engineered unique internal restriction site. Its inclusion enables normalization between reactions and a measurement of the absolute number of target hnRNA transcripts. Specificity for the hnRNA was achieved by using introndirected primers in both the $R T$ and the $P C R$. Nuclear run-on assays and the hnRNA RT-PCR assay detected an equivalent increase in transcription of Cyp 1a-1 in cultured murine Hepa $1 \mathrm{clc} 7$ cells following exposure to 2,3,7,8-tetrachlorodibenzo-pdioxin (TCDD). The RT-PCR assay also revealed TCDD-dependent transcriptional activation of the Cypla-1 gene in murine skin, a tissue unsuited to the nuclear run-on assay because of inherent difficulties associated with the isolation of nuclei. These examples demonstrate that the hnRNA RT$P C R$ assay is a facile surrogate for the nuclear run-on assay. Moreover, the sensitivity and design characteristics of the RT$P C R$ assay suggest the potential for its broad application in general transcriptional research.

\section{INTRODUCTION}

The predominant method used to examine the transcriptional status of a given gene is the in vitro nuclear run-on assay. However, it embodies several significant constraints that limit its usefulness. The assay is laborious, timeconsuming, expensive and involves significant amounts of radioactivity. Most notably, it requires large numbers of isolated nuclei, restricting it to systems where adequate numbers of nuclei can be isolated. Furthermore, obtaining reproducible data is difficult particularly in situations where gene transcription is low. The advent of a more amenable method to examine gene transcription would be desirable.

Quantitative reverse transcription polymerase chain reaction (RT-PCR) amplification of cellular messenger RNA (mRNA) is increasingly used to study gene expression, especially when tissue samples are limiting. However, analyses of mRNA provide only an indirect account of gene transcription, since mRNA levels represent the sum of both transcriptional and post-transcriptional events (e.g., processing, degradation). Heterogeneous nuclear RNAs (hnRNA) are nascent, as yet unspliced transcripts. In principle, measuring hnRNA levels may prove useful in determining a gene's transcriptional state. In fact, several reports suggest that RT-PCR on hnRNA might serve as a complementary approach to the nuclear run-on assay, but adequate experimental support for this idea was never provided $(3,6,11,19)$.
This report describes a simple, quantitative RT-PCR-based strategy to amplify hnRNA for use as a transcriptional index of any gene of interest. We used this strategy to investigate the transcriptional activation of Cypla- 1 in cultured murine Hepa 1c1c7 cells and in vivo in murine keratinocytes. Accumulation of the cytochrome $\mathrm{P} 450$ CYP1A1 protein in response to xenobiotics such as 2,3,7,8-tetrachlorodibenzo- $p$-dioxin (TCDD, dioxin) is a consequence of transcriptional activation of the Cypla-1 gene $(8,18)$. The well-characterized transcriptional response of Cypla-1 to TCDD in the Hepa cells (18) provided an excellent model in which to develop and validate the RT-PCR transcriptional assay. In turn, the keratinocytes provided a test case for the assay since Cyp 1 - 1 induction occurs primarily in differentiating keratinocytes, from which it is virtually impossible to isolate nuclei (12). We consider this application of the RT-PCR strategy a facile surrogate for the in vitro transcription nuclear run-on assay offering several significant advantages over the run-on assay.

\section{MATERIALS AND METHODS}

\section{Internal Standard Cloning Vectors}

PstI-digested pBluescript ${ }^{\circledR}$ II KS $(+)$ (Stratagene, La Jolla, CA, USA) was tailed with adenosines using terminal deoxynucleotidyl transferase (TdT) and dATP from Boehringer Mannheim (Indianapolis, IN, USA) (Figure 1). Polyadenylated vectors were PCR- 
amplified using an oligo(dT) primer harboring an $\mathrm{XbaI}$ restriction site (see Table 1). PCR products were digested with either SmaI or EcoRV to remove the polyadenosine sequence from either vector arm, and the vector circularized in the presence of T4 DNA ligase (Life
Technologies, Gaithersburg, MD, USA). DNA sequence analysis of individual clones using Sequenase ${ }^{\circledR}$ Version 2.0 (United States Biochemical, Cleveland, $\mathrm{OH}, \mathrm{USA}$ ) identified clones with 21-90 nucleotide polyadenosine cassettes in either orientation.

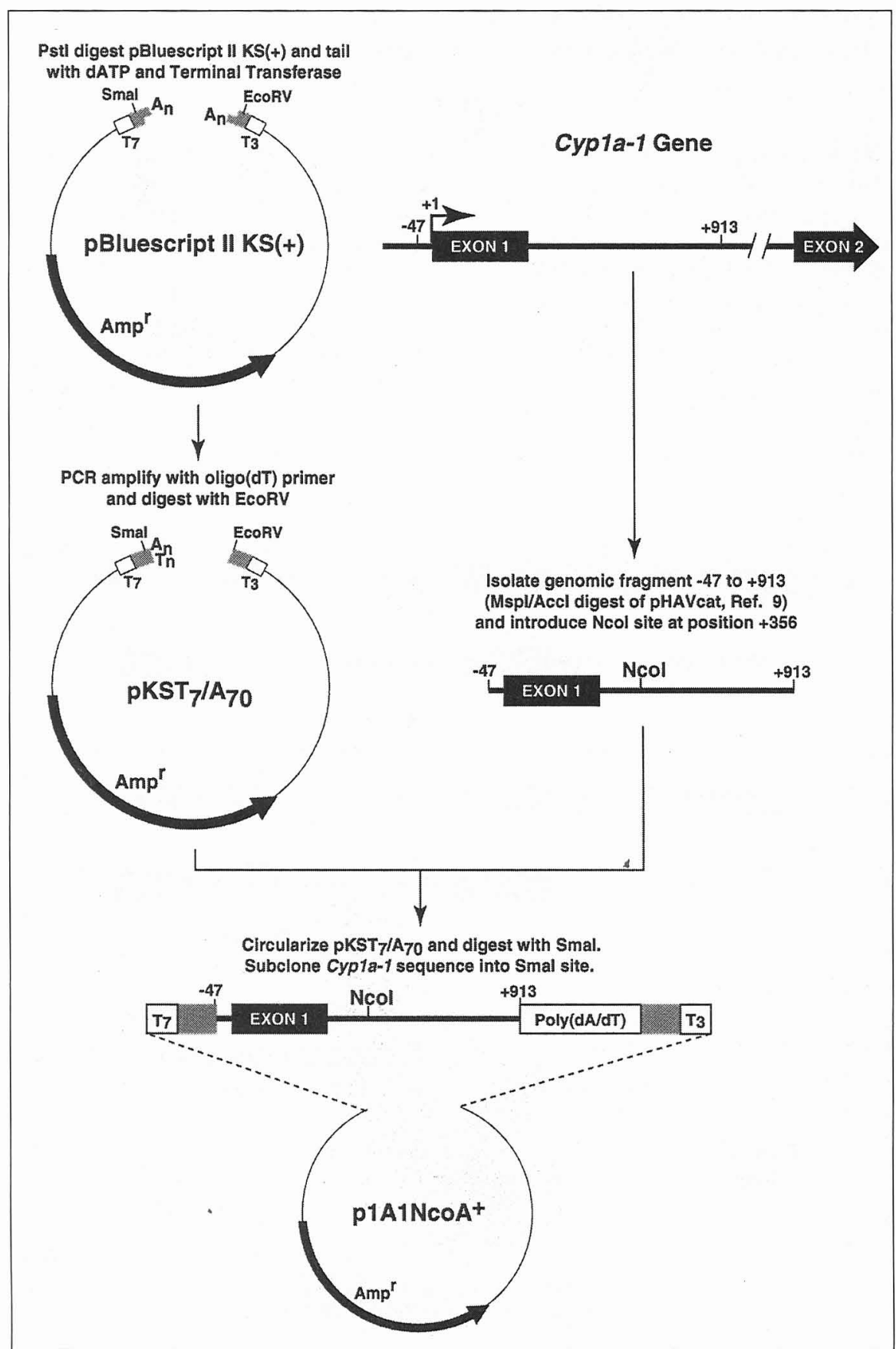

Figure 1. Scheme for the synthesis of the internal standard plasmid. The left half depicts the strategy for adding the polyadenosine tails to pBluescript II $\mathrm{KS}(+)$, followed by PCR amplification using an oligo(dT) primer against the polyadenosine tails. Polyadenosines were removed from either vector arm using EcoRV (shown as pKST $/ \mathrm{A}_{70}$ ) or SmaI (not shown). The Cypla-1 genomic sequence depicted on the right was subcloned into $\mathrm{pKST}_{7} / \mathrm{A}_{70}$ after introducing the $\mathrm{NcoI}$ site at position +356 to generate the internal standard rcRNA construct $\mathrm{p} 1 \mathrm{~A} 1 \mathrm{NcoA}^{+}$.

\section{Synthesis of the Cyp1a-1 Internal Standard Sequence}

The 960-bp AccI/MscI fragment from pHAVCat (9), representing nucleotides -47 to +913 of the Cyp $1 a-1$ gene, was end-filled and subcloned into SmaI-cut pBluescript II KS(+). A partial $B s a \mathrm{HI}$ digestion (BsaHI cuts once within both the insert and vector) of a subclone containing the Cypla-1 sequence in the correct orientation, and subsequent gel isolation of the $3.9-\mathrm{kb}$ product, was followed by dephosphorylation of the DNA ends with calf intestinal phosphatase (Boehringer Mannheim) and ligated in the presence of $1 \mu \mathrm{g} \mathrm{NcoI} \mathrm{linkers} \mathrm{(New} \mathrm{England}$ Biolabs, Beverly, MA, USA). Individual clones were screened for integration of an $\mathrm{NcoI}$ site into the insert (at position 356 in the Cypla-1 gene sequence) by restriction analysis. The Cyp $1 a-1$ sequence, excised with EcoRI and BamHI, was end-filled and introduced into $S m a \mathrm{I}$ cut $\mathrm{pKST}_{7} / \mathrm{A}_{70}$ to generate the RT-PCR internal standard plasmid p1A1NcoA ${ }^{+}$(Figure 1).

\section{In Vitro Transcription of the Internal Standard}

Ten microliters of HindIII-linearized p1A1NcoA ${ }^{+}$DNA $(0.2 \mu \mathrm{g} / \mu \mathrm{L})$ were added to a $10-\mu \mathrm{L}$ volume of reaction mixture containing $\mathrm{T} 7$ transcription buffer, $1 \mathrm{mM}$ of each ribonucleoside triphosphate $(0.5 \mathrm{mM}$ final concentration) and 2 units T7 RNA polymerase (all from Boehringer Mannheim). Transcription occurred at $30^{\circ} \mathrm{C}$ for $1 \mathrm{~h}$. Following phenol/chloroform extraction and ethanol precipitation, the recombinant complementary RNA (rcRNA) was purified by oligo(dT)-Sepharose ${ }^{\circledR}$ (Pharmacia Biotech, Piscataway, NJ, USA) chromatography (2), quantified spectrophotometrically and stored at $-80^{\circ} \mathrm{C}$ as single-use aliquots containing $10^{8}$ rcRNA molecules/ $\mu \mathrm{L}$.

\section{Cell Culture and Total RNA Extraction}

Hepa $1 \mathrm{c} 1 \mathrm{c} 7$ cells were grown in 100 -mm plates as previously described (13) and exposed to TCDD (5 nM, $1 \mathrm{~h}$ ) or dimethyl sulfoxide (DMSO) (vehicle) for $1 \mathrm{~h}$. For the RT-PCR, $\alpha$ amanitin (Sigma Chemical, St. Louis, 
MO, USA) was added to the media at a final concentration of $2 \mu \mathrm{g} / \mathrm{mL}, 1 \mathrm{~h}$ post-TCDD treatment. The dorsa of outbred female SENCAR mice (National Cancer Institute, Frederick, MD, USA) were shaved 5-7 days prior to use. Mice were sacrificed, and the dorsa were excised at various times following topical treatment of the areas with acetone $(200 \mu \mathrm{L})$ or TCDD (4 nmol in acetone). After removal of the fat pad, the skin pelts were cut into strips, quick-frozen in liquid nitrogen and ground with a mortar and pestle. RNA extraction from cultured cells and skin used the method of Chirgwin et al. (4), except that the samples were centrifuged at $55000 \mathrm{rpm}$ for $2.5 \mathrm{~h}$ in a TLS-55 rotor (Beckman Instruments, Fullerton, CA, USA). RNA was stored at $-80^{\circ} \mathrm{C}$.

\section{Northern Analysis}

Total RNA from mouse keratinocytes ( $20 \mu \mathrm{g}$ per lane), or the internal standard rcRNA $(1 \mu \mathrm{g})$, was electrophoresed in a $1.2 \%$ formaldehydeagarose gel and transferred to a nitrocellulose membrane (Schleicher \& Schuell, Keene, NH, USA) by capillary transfer and UV-fixed in a Stratalinker ${ }^{\circledR}$ UV cross-linker (Stratagene). Membranes were prehybridized at $50^{\circ} \mathrm{C}$ for $3 \mathrm{~h}$ and hybridized at $50^{\circ} \mathrm{C}$ overnight with $10^{6} \mathrm{cpm} / \mathrm{mL}$ probe in $6 \times$ sodium chloride sodium phosphate EDTA (SSPE), $5 \times$ Denhardt's, $1 \%$ sodium dodecyl sulfate (SDS) and $100 \mu \mathrm{g} / \mathrm{mL}$ tRNA. The CYP1A1 probe was a ${ }^{32} \mathrm{P}-$ random primer labeled (Life Technologies) 700-bp Cypla-1-encoding Pst $\mathrm{I}$ fragment (10). A T4 Polynucleotide Kinase (New England Biolabs) ${ }^{32} \mathrm{P}-\mathrm{end}-$ labeled RTase primer (see Table 1) served as a probe for the internal standard rcRNA transcript. Filters were washed in $1 \times$ standard sodium citrate (SSC) containing $0.1 \%$ SDS at RT for $30 \mathrm{~min}$ followed by. $1 \times$ SSC containing $0.1 \% \mathrm{SDS}$ at $42^{\circ} \mathrm{C}$ for $30 \mathrm{~min}$ and exposed to X-ray film (Kodak XAR-5; Eastman Kodak, Rochester, NY, USA).

\section{Quantitative RT-PCR on hnRNA and Product Analysis}

Reverse transcription was carried out using SuperScript ${ }^{\mathrm{TM}}$ II (Life Technologies) using conditions described by
Table 1. RT and PCR Primer Sequences

\begin{tabular}{|llc|}
\hline & Primer Sequence & $\begin{array}{c}\text { Nucleotide* } \\
\text { Position }\end{array}$ \\
\hline Oligo(dT) primer & 5'-GCTCTAGAGCTTTTTTTTTTTTTTTTT-3' & Not Applicable \\
RTase primer & $5^{\prime}$-TGCTTAATTCAGAGGGCTACAGATCC-3' & $809-834$ \\
Forward primer & 5'-GGTCCTAGAGAACACTCTTCACTTCAGTC-3' & $678-700$ \\
Reverse primer & 5'-TAATTGGTGTCCCTAAGGAACCC-3' & $42-70$ \\
*Numbering refers to the Cyp1a-1 structural gene. & \\
\hline
\end{tabular}

the manufacturer. The RTase primer was annealed to a mixture containing 1-2 $\mu \mathrm{g}$ Hepa 1c1c7 cells or keratinocyte total RNA and $5 \times 10^{6}$ copies of the internal standard reRNA. Following a $1 \mathrm{~h} / 37^{\circ} \mathrm{C}$ incubation, the reaction was terminated at $70^{\circ} \mathrm{C}$ for $15 \mathrm{~min}$ and diluted to $250 \mu \mathrm{L}$ with water. The cDNA was either used immediately in the PCR or stored at $-20^{\circ} \mathrm{C}$. PCR was performed using $5 \mu \mathrm{L}$ of the diluted
cDNA in a final reaction volume of $50 \mu \mathrm{L}$ using a forward primer and a "nested" reverse primer specific for the Cypla-1 gene's first exon and intron, respectively (Table 1). PCR was initiated by adding $25 \mu \mathrm{L}$ of a $2 \times$ master mixture containing $20 \mathrm{mM}$ Tris$\mathrm{HCl}, \mathrm{pH} 8.3$ (at $25^{\circ} \mathrm{C}$ ), $100 \mathrm{mM} \mathrm{KCl}, 5$ $\mathrm{mM} \mathrm{MgCl}_{2}, 0.002 \%$ gelatin, $400 \mu \mathrm{M}$ each of four dNTPs (dATP, dCTP, dGTP, dTTP), $5 \mu \mathrm{Ci}$ dCTP $(3000$

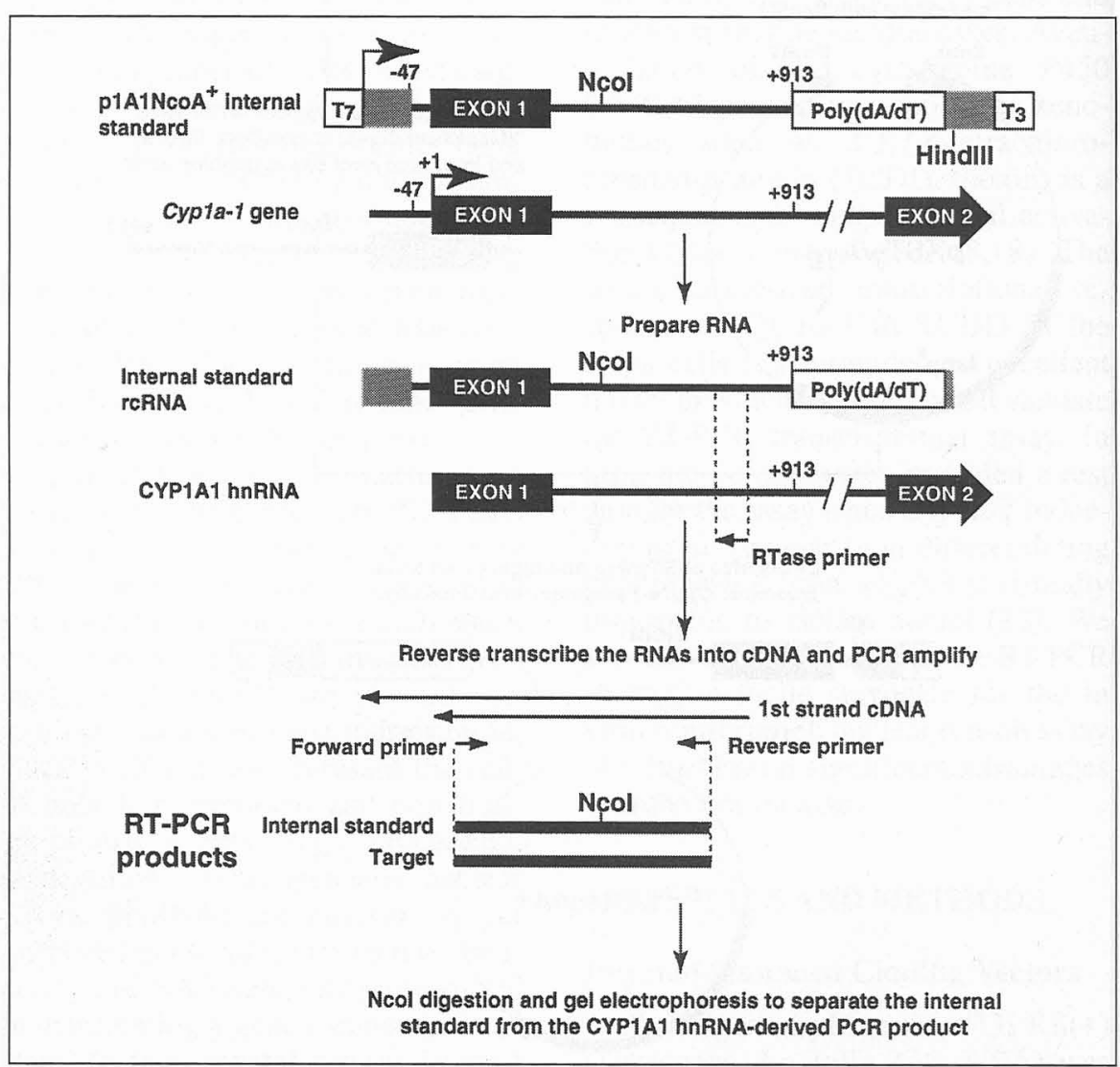

Figure 2. Scheme for the RT-PCR assay. Depicted are the internal standard $\left(\mathrm{p} 1 \mathrm{~A} 1 \mathrm{NcoA}{ }^{+}\right)$and genomic target DNA sequences for Cyp 1a-1 and corresponding rcRNA and hnRNAs, respectively. A mixture of rcRNA and hnRNA was reverse-transcribed into cDNA using the RTase primer (nucleotides 809-834). PCR used a forward primer (42-70) and reverse primer (678-700) to amplify the cDNA. This was followed by NcoI digestion of the internal standard and fractionation of the products on a non-denaturing $5 \%$ polyacrylamide gel and visualized by autoradiography. 
$\mathrm{Ci} / \mathrm{mmol}$; Du Pont NEN, Boston, MA, USA), $400 \mathrm{nM}$ of both the forward and reverse primer and 1 unit AmpliTaq ${ }^{\circledR}$ DNA Polymerase (Perkin-Elmer, Norwalk, CT, USA) to the cDNA $(25 \mu \mathrm{L})$ at $95^{\circ} \mathrm{C}$. PCR was performed using the GeneAmp ${ }^{\mathrm{TM}}$ PCR System 9600 from Perkin-Elmer, cycling at $95^{\circ} \mathrm{C} / 15 \mathrm{~s}$ (strand separation), $60^{\circ} \mathrm{C} / 20 \mathrm{~s}$ (annealing) and $72^{\circ} \mathrm{C} / 45 \mathrm{~s}$ (extension) for 30 cycles (except where indicated differently) with a final 10-min extension. Ten units of $\mathrm{NcoI}$ were added directly to the PCR tubes and incubated at $37^{\circ} \mathrm{C}$ for at least $1 \mathrm{~h}$. Products were analyzed by fractionating $10 \mu \mathrm{L}$ of the PCR on a nondenaturing $5 \%$ polyacrylamide/ TBE (TBE $=45 \mathrm{mM}$ Tris-borate, $1 \mathrm{mM}$ EDTA, pH 8.0) gel followed by autoradiography of the dried gel. The absence of PCR products following the PCR on non-reverse-transcribed total RNA served as a routine check for contaminating genomic DNA.

\section{In Vitro Transcription Nuclear Run- On Assay}

Isolation of nuclei from Hepa 1c1c7 cells and the run-on assay were performed essentially as described previously $(1,5)$. Briefly, $1.5 \times 10^{7}$ isolated nuclei $(50 \mu \mathrm{L})$ were added to 100 $\mu \mathrm{L} 75 \mathrm{mM}$ Tris- $\mathrm{HCl}, 7.5 \mathrm{mM} \mathrm{MgCl}{ }_{2}$, $225 \mathrm{mM} \mathrm{KCl}, 1.5 \mathrm{mM}$ dithiothreitol,

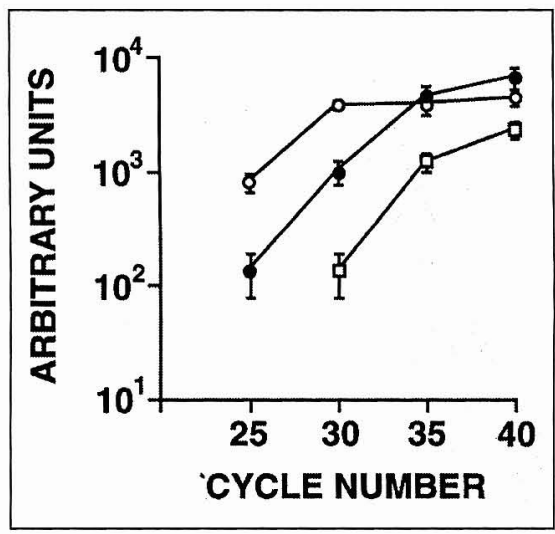

Figure 3. RT-PCR product formation as a function of cycle number and template concentration. In vitro derived internal standard rcRNA transcripts were purified by oligo(dT) chromatography and used in RT-PCR at $6 \times 10^{3}$ (open squares), $6 \times 10^{4}$ (solid circles) and $6 \times 10^{5}$ (open circles) input molecules for $25-40$ cycles. Undigested PCR products were gel-fractionated and visualized autoradiographically. Bands were quantified by densitometric analysis on scanned autoradiographs.
$1.5 \mathrm{mM} \mathrm{MnCl} 2,3 \mu \mathrm{M}$ UTP, $1.5 \mathrm{mM}$ ATP, $1.5 \mathrm{mM}$ CTP, $1.5 \mathrm{mM}$ GTP and $100 \mu \mathrm{Ci}[\alpha-32 \mathrm{P}] \mathrm{UTP}(3000 \mathrm{Ci} / \mathrm{mmol})$, $\mathrm{pH} 7.9$, and incubated for $30 \mathrm{~min}$ at $26^{\circ} \mathrm{C}$. The reaction was stopped with $750 \mu \mathrm{L} 0.5 \%$ SDS and $900 \mu \mathrm{L} 100 \mathrm{mM}$ $\mathrm{Na}$ acetate (pH 5.0). Radiolabeled RNA was prepared as described (16), and radiolabeled ribonucleotide incorporation was determined by TCA precipitation (5) using tRNA as carrier. Denatured, gel-purified insert DNA $(2 \mu \mathrm{g})$ from $\mathrm{p} 1 \mathrm{~A} 1 \mathrm{Nco} \mathrm{A}^{+}$and a $\beta$-actin clone (8) was immobilized onto Nytran ${ }^{\circledR}$ membranes (Schleicher \& Schuell) by "slot-blotting". Blots were prehybridized overnight in $6 \times$ SSPE, $5 \times$ Denhardt's, $0.1 \%$ SDS, $0.1 \%$ Na pyrophosphate, $100 \mu \mathrm{g} / \mathrm{mL}$ tRNA, pH 7.6, at $52^{\circ} \mathrm{C}$. Hybridizations were carried out in fresh hybridization solution containing $2 \times 10^{6} \mathrm{cpm}$ radiolabeled RNA at $52^{\circ} \mathrm{C}$ for $72 \mathrm{~h}$. Filters were washed twice in $2 \times$ SSC containing $0.1 \%$ SDS at room temperature for $30 \mathrm{~min}$ and once in $0.2 \times$ SSC containing $0.1 \%$ SDS at $65^{\circ} \mathrm{C}$ for $30-60 \mathrm{~min}$. Filters were dried and exposed to X-ray film (Kodak XAR-5).

\section{Data Quantitation}

Autoradiographs were scanned using a Silverscanner II flatbed scanner with a transparency adaptor ( $\mathrm{La} \mathrm{Cie,}$ Beaverton, OR, USA), and quantitative analyses were performed on a Macintosh ${ }^{\circledR}$ Quadra 650 computer using the program NIH Image (Version 1.54). This program is written by Wayne Rasband and is available in the public domain. The hnRNA copy number is obtained by acquiring a densitometric value for both the target hnRNA and internal standard. Knowing the internal standard copy number, the signal ratios are used to determine the hnRNA copy number.

\section{RESULTS}

\section{Quantitative RT-PCR on CYP1A1 hnRNA}

Quantitative RT-PCR most frequently involves inclusion of an RNA internal standard. Plasmid p1A1NcoA ${ }^{+}$ encodes a portion of the Cypla-1 gene encompassing the first intron-exon boundary, corresponding to the region of interest in the target sequence (Figure 1). The poly $(\mathrm{dA} / \mathrm{dT})$ cassette located immediately downstream from the Cypla-1 sequence permits the in vitro synthesis of polyadenylated transcripts from the T7 RNA polymerase promoter. These are readily purified by standard oligo(dT) chromatography (2) and quantitated, and the transcript copy number is calculated from the known sequence length. Chromatography also removes DNA template and any truncated transcripts lacking the poly(A) tail. Northern analysis performed with a [ $\gamma$-32P]ATP end-labeled' oligonucleotide probe (RTase primer) confirmed that the internal standard rcRNA was full-length (results not shown).

The principle of quantitative RTPCR and rationale behind the design and requirement for internal standards is well documented $(15,17)$. To ensure reliable quantitation with the RT-PCR strategy (Figure 2), the PCR must not exceed the exponential phase of the amplification. Quantitation of RT-PCR products obtained after 25-40 cycles using a 100-fold range of internal standard rcRNA transcripts provided an empirical determination of the exponential phase (Figure 3). Amplification of $6 \times 10^{3}$ to $6 \times 10^{5}$ initial rcRNA copies remained exponential for at least 30 cycles. Based on product formation as a function of cycle number, the PCR efficiency was calculated to be $60 \%$ using the formula derived by Trapnell (14). Since the rcRNA internal standard and Cypla-1 hnRNA target sequence are almost identical, RT-PCR amplification of the hnRNA target should occur with the same efficiency. This ensures that the PCR parameters that define exponential amplification of the internal standard also apply to the target sequence.

\section{Cyp1a-1 Transcription Measured by the Run-On and RT-PCR Assays}

Nuclei for the transcription run-on assay and total RNA for RT-PCR analyses were isolated from Hepa $1 \mathrm{c} 1 \mathrm{c} 7$ cell cultures treated with TCDD under conditions that maximally induce Cypla- 1 transcription. The two methods detect quantitatively equivalent 
increases in TCDD-induced Cypla-1 gene expression (Figure 4). The minor difference in fold induction is not statistically significant according to a twosample Student's $t$ test. Whereas run-on data only provide information on relative transcriptional rates, the RT-PCR internal standard permits determination of the absolute number of hnRNA molecules per $\mu \mathrm{g}$ of total RNA. In fact, based on a total RNA recovery of $50 \mu \mathrm{g}$ from $5 \times 10^{6}$ cells, we are detecting $1-2$ and 8-10 copies per cell of the CYP1A1 hnRNA in untreated and TCDD-treated cells, respectively.

Since hnRNAs are transient intermediates, their concentration at any time reflects a steady-state equilibrium between transcription and processing (splicing). Therefore, changes in the hnRNA level may reflect alterations in transcription or the rate of splicing to mature transcripts. $\alpha$-Amanitin is a potent inhibitor of RNA polymerase II (3). CYP1A1 hnRNA processing at the first intron-exon boundary was determined to have a $\mathrm{T}_{1 / 2}=34 \mathrm{~min}$ in $\alpha$ amanitin-treated cultures (Figure 5). Since CYP1A1 hnRNA levels remain constant for at least $4 \mathrm{~h}$ in the absence of $\alpha$-amanitin (results not shown), the loss of transcript is not simply due to a spontaneous decrease in Cypla-I transcription. These results are consistent with a constant turnover of nascent transcripts and demonstrate that transcription and hnRNA processing can be readily dissociated in this assay. Experiments using $\alpha$-amanitin concentrations ranging from $1-10 \mu \mathrm{g} / \mathrm{mL}$ consistently gave the same $T_{1 / 2}$ value, suggesting that Cypla-1 transcription was maximally suppressed even at the low $\alpha$ amanitin concentration (results not shown). A previous report indicated that RNA polymerase II transcription is inhibited by $98 \%$ in the presence of 2 $\mu \mathrm{g} / \mathrm{mL} \alpha$-amanitin (3).

\section{Cyp1a-1 Expression in Mouse Keratinocytes}

The original objective behind the development of this RT-PCR assay stems from our desire to study Cyp la-I transcription in skin. Previous investigation in the laboratory has demonstrated that the TCDD-mediated induction of Cypla-1 occurs mostly in differentiating keratinocytes (12). Nor- thern analysis reveals that steady-state CYP1A1 mRNA levels are dramatically elevated in murine skin within $1 \mathrm{~h}$ following topical administration of TCDD (Figure 6). The RT-PCR assay similarly detected an increase in CYP1A1 hnRNA content following TCDD application, which was consistent with a persistent increase in gene transcription. Therefore, the RT-PCR assay provides a tool to examine Cyp 1a-1 gene transcription in these cells as a function of their differentiation while simultaneously demonstrating its potential as a surrogate for the transcription run-on assay.

\section{DISCUSSION}

This report describes a quantitative RT-PCR assay for the analysis of

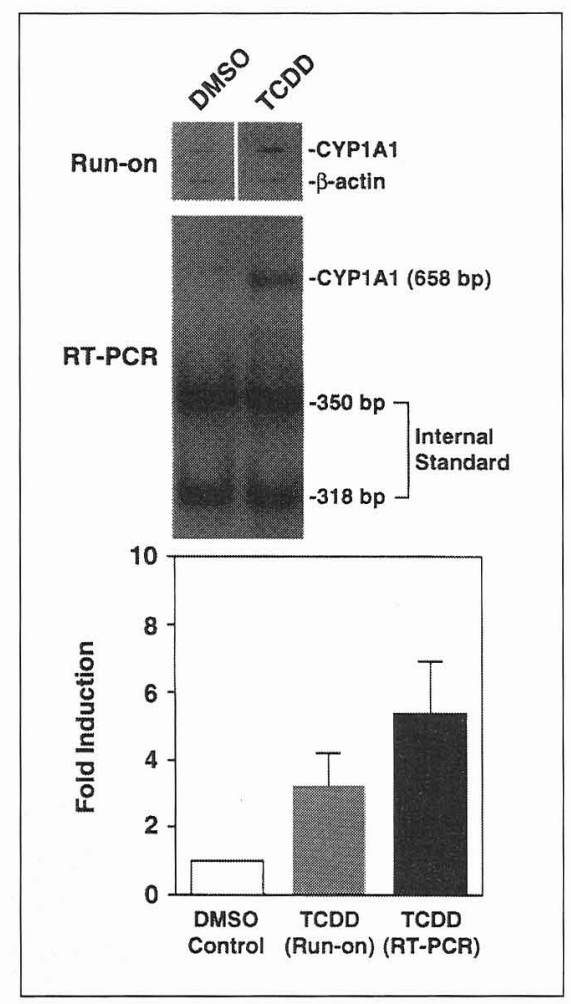

Figure 4. Comparison between the transcription run-on and RT-PCR assay. Hepa 1c1c7 cells treated with DMSO (vehicle) or $5 \mathrm{nM}$ TCDD (in DMSO) for $1 \mathrm{~h}$ were used to isolate nuclei or total RNA. The top panel presents the results obtained by the run-on assay with nuclei and RT-PCR assay on hnRNA from the same batch of cells. The bottom panel presents quantitative analyses of the data obtained in three independent experiments. Run-on data and the RTPCR data were normalized against $\beta$-actin and the internal standard PCR product, respectively. Error bars denote the standard error of the mean. nascent CYP1A1 hnRNA transcripts. Specificity for CYP1A1 hnRNA is obtained by using an intron-directed primer in the RT reaction and a nested PCR primer (i.e., reverse primer) complementary to an upstream intronic sequence (Figure 2). Using a specific intronic primer, as opposed to oligo(dT) in the RT reaction, avoids amplification of mature mRNAs and the need to reverse-transcribe very long sequences. It also obviates possible complications arising from intron processing and removal prior to hnRNA polyadenylation. Quantitativeness of the assay is achieved by inclusion throughout the RT-PCR protocol of a CYP1A1 rcRNA internal standard that is nearly identical to the target hnRNA transcript. The sequence similarity should ensure that both RNAs are copied with equal efficiency during the RT reaction and during the exponential phase of the PCR. Consequently, absolute quantitation of CYP1A1 hnRNA sequences in the test RNA sample can be calculated simply from the ratio between the target and internal standard PCR products, irrespective of the efficiencies of the RT reaction or PCR. The internal standard also renders inter-sample comparisons more meaningful since it obviates the confounding effects of differences in RT and PCR efficiencies that may occur between samples.

Introduction of a unique $\mathrm{NcoI}$ re-

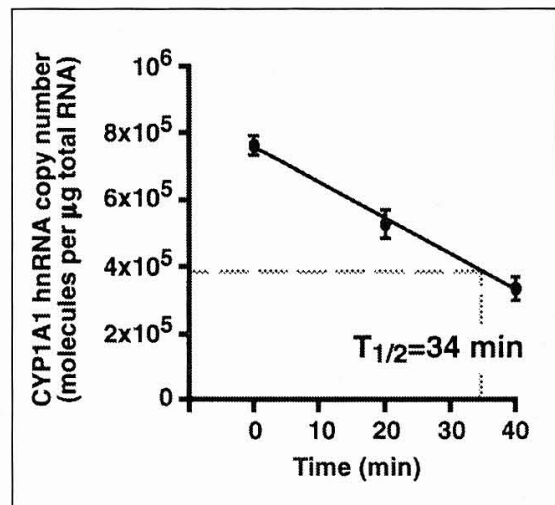

Figure 5. CYP1A1 hnRNA half-life. Hepa $1 \mathrm{clc} 7$ cells were treated with $5 \mathrm{nM}$ TCDD for $1 \mathrm{~h}$ prior to the addition of $2 \mu \mathrm{g} / \mathrm{mL} \alpha$-amanitin. Total RNA was extracted thereafter at the indicated times and subjected to quantitative RT-PCR. Data from three independent experiments were normalized against the internal standard and represent the mean value \pm standard error of the mean. 
striction site into the CYP1A1 internal standard rcDNA provides a method whereby the PCR products corresponding to the internal standard and target hnRNA can be resolved from one another. However, accurate quantitation of the target transcript assumes that the internal standard is digested to completion following exposure to $\mathrm{NcoI}$, since uncut internal standard co-migrates with the target sequence leading to overestimates of the target transcript. In our experience, based upon performing the PCR as replicate samples, incomplete digestion of the internal standard PCR product has not proven to be a problem. A second potential complica- tion to quantitation is heteroduplex formation between internal standard and target sequence PCR products. Such products cannot be cut. This represents a legitimate concern only if the PCR is allowed to proceed beyond the exponential phase, when DNA templates can reanneal without replication. This issue is easily addressed by limiting the PCR to the exponential phase of the reaction (Figure 3). Others $(15,17)$ report using a truncated internal standard that is distinguishable from the target sequence without the need for DNA digestion. The potential for an altered internal standard sequence to possess different RT and PCR efficiencies from

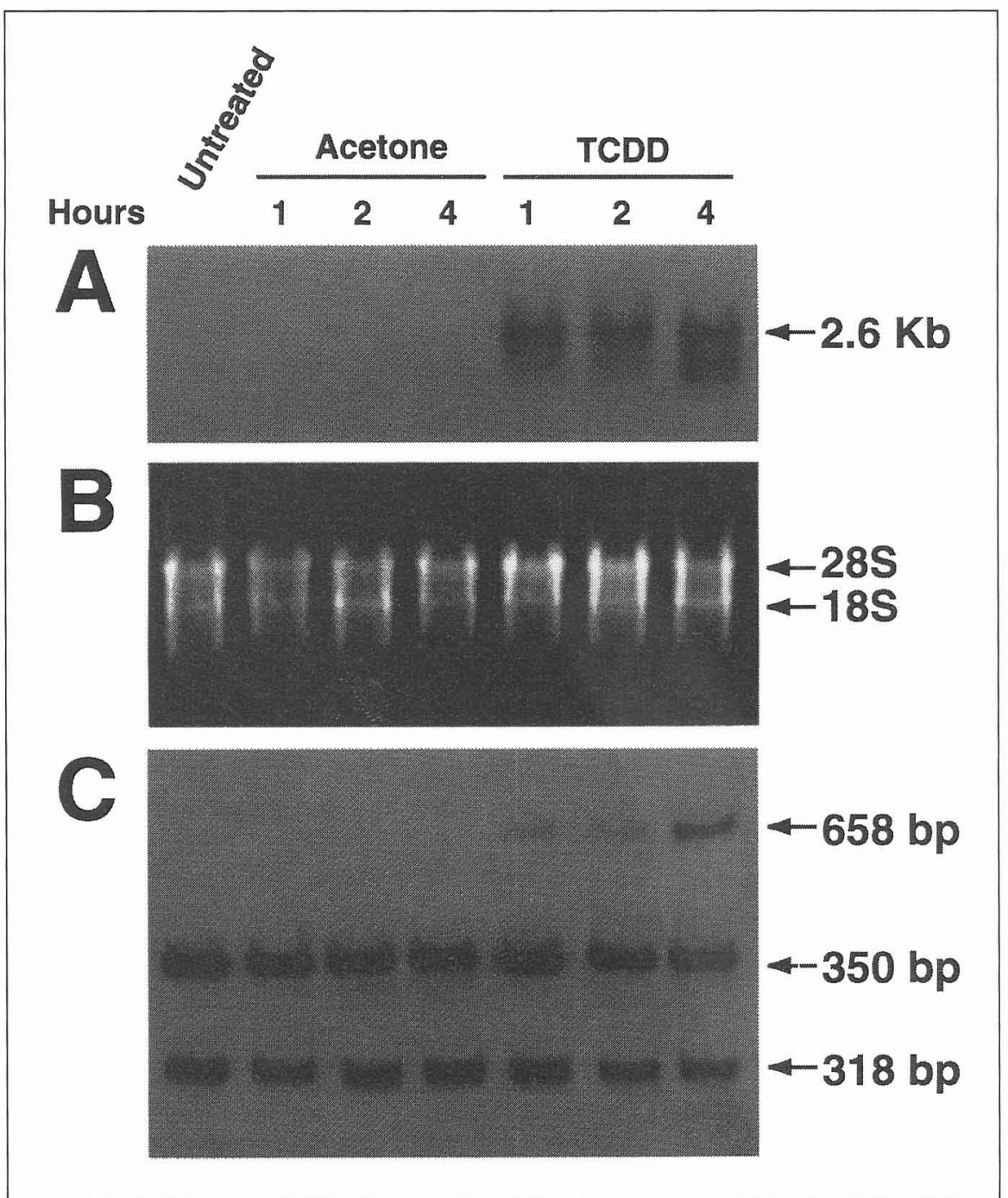

Figure 6. Cyp1a-1 induction in mouse keratinocytes. Total RNA was extracted from the skins of control mice (lane 1) or mice treated for 1-4 h with either acetone (lanes 2-4) or $4 \mathrm{nmol}$ TCDD (lanes 5-7). $20 \mu \mathrm{g}$ of total RNA were fractionated on a $1.2 \%$ agarose-formaldehyde gel and stained with ethidium bromide (Panel B) prior to transfer to nitrocellulose for detection of CYP1A1 mRNA (Panel A). Quantitative RT-PCR on CYP1A1 hnRNA (Panel C) was performed on $1 \mu \mathrm{g}$ total RNA. 
the target sequence, thereby compromising assay quantitation, renders this strategy less desirable.

RT-PCR and nuclear run-on assays of Cypla-1 transcription in Hepa cultures gave quantitatively similar results in multiple analyses, each performed on a single batch of cells (Figure 4). This supports our contention that the assay is a potential surrogate for the in vitro transcription nuclear run-on assay. Variability between the RT-PCR experiments was less than $30 \%$, suggesting that the assay should readily detect modest changes in transcription rate (e.g., 2-fold). The inherent difficulty of isolating nuclei that retain the true physiological transcription status renders run-on assays more susceptible to experimental variation.

Studies using the RT-PCR assay assume that changes in the amount of a given hnRNA sequence reflect trans- criptional events instead of an altered processing rate. Transcription inhibitors such as $\alpha$-amanitin can be used to dissociate these processes (Figure 5). If hnRNA processing rates are unaffected, then changes in the level of a given hnRNA can be directly attributed to a transcriptional event. Additionally, RT-PCR could be used to also quantify the corresponding mature mRNA levels. In this event, a proportional change in hnRNA and mRNA levels is consistent with a constant processing rate. Conversely, a disproportionate accumulation of either RNA species is indicative of a change in the rate of RNA processing. These relationships are only meaningful, however, if mRNA degradation is unaffected.

Detection of CYP1A1 hnRNA transcripts in murine keratinocytes by the RT-PCR assay paralleled the TCDD-induced increase in mRNA, consistent with a transcriptional res- ponse (Figure 6). This system represents a practical example of where runon assays are unfeasible due to inherent difficulties with the isolation of nuclei; and RT-PCR of hnRNA functions as a surrogate assay for assessment of the transcriptional activation of a gene. In principle, the assay could be adopted to analyze any hnRNA providing that genomic sequence information and suitable primer sites are available. In addition, the polyadenosine cassettecontaining cloning vectors we generated will simplify the preparation of internal standard rcRNA sequences. By using suitable PCR primers, an internal standard can be prepared containing both a unique restriction site and appropriate restriction sites for insertion into the vector MCS.

The exquisite sensitivity of the RTPCR assay renders it suitable even with small tissue samples comprising only tens of thousands of cells. The RT-PCR 
studies reported here were performed on 1-2 $\mu \mathrm{g}$ total RNA, representing an estimated $1-2 \times 10^{5}$ cells. However, only a fraction of the cDNA-equivalent to $20 \mathrm{ng}$ total RNA-was amplified by PCR. In situations where cell number or absolute RNA concentrations cannot be determined, quantitative genomic Southern analysis using a repetitive DNA sequence probe (e.g., Alu sequence) has been used to enumerate human cells with the intent of establishing absolute cellular transcript levels (14). Such an approach might facilitate the use of the hnRNA RTPCR assay to study the transcriptional activation of genes in tissues of limited sample size, such as embryonic tissue or in the analyses of clinical biopsy samples. The hnRNA RT-PCR assay may also be a useful tool for addressing other issues. For instance, in hnRNA splicing studies, both the rate and the sequential order of intron splicing in a given gene could be determined without reliance on the traditional approaches of Northern analysis, S1 nuclease or RNase protection assays. Alternatively, expression of a reporter construct in transient transfection studies could be used to measure actual transcriptional events, without concern that RNA stability, translation, protein stability or enzyme activity of a reporter is affected by experimental manipulation.

\section{ACKNOWLEDGMENTS}

This work was supported by Grant CA34469 awarded by the National Institutes of Health. The technical assistance of Nancy Hong is greatly appreciated. We thank Drs. R. Hines and $\mathrm{T}$. Kocarek for their comments on the manuscript.

\section{REFERENCES}

1.Alterman, R-B.M., S. Ganguly, D.H. Schulze, W.F. Marzluff, C.L. Schildkraut and A.I. Skoultchi. 1984. Cell cycle regulation of mouse $\mathrm{H} 3$ histone mRNA metabolism. Mol. Cell. Biol. 4:123-132.

2.Aviv, H. and P. Leder. 1972. Purification of biologically active globin messenger RNA by chromatography on oligothymidylic acid-cellulose. Proc. Natl. Acad. Sci. USA 69:14081413.

3.Chang, C-D., P. Phillips, K.E. Lipson, V.J.
Cristofalo and R. Baserga. 1991. Senescent human fibroblasts have a post-transcriptional block in the expression of the proliferating cell nuclear antigen gene. J. Biol. Chem. 266:8663-8666.

4.Chirgwin, J.M., A.E. Przybyla, R.J. MacDonald and W.J. Rutter. 1979. Isolation of biologically active ribonucleic acid from sources enriched in ribonucleases. Biochemistry 18:5294-5299.

5.Elferink, C.J., S. Sassa and B.K. May. 1988. Regulation of 5-aminolevulinate synthase in mouse erythroleukemic cells is different from that in liver. J. Biol. Chem. 263:13012-13016.

6.Ferrari, S. and R. Battini. 1990. Identification of chicken Calbindin $\mathrm{D}_{28 \mathrm{~K}}$ pre-messenger RNA sequences by the polymerase chain reaction. Biochem. Biophys. Res. Comm. 168:430-436.

7.Green, M.R. 1991. Biochemical mechanisms of constitutive and regulated pre-mRNA splicing. Annu. Rev. Cell Biol. 7:559-599.

8.Israel, D.I. and J.P. Whitlock, Jr. 1984. Regulation of cytochrome $\mathrm{P}_{1}-450$ gene transcription by 2,3,7,8-tetrachlorodibenzo-p-dioxin in wild type and variant mouse hepatoma cells. J. Biol. Chem. 259:5400-5402.

9.Jones, P.B.C., D.R. Galeazzi, J.M. Fisher and J.P. Whitlock, Jr. 1985. Control of cytochrome $P_{1}-450$ gene expression by dioxin. Science 227:1499-1502

10.Negishi, M., D.C. Swan, L.W. Enquist and D.W. Nebert. 1981. Isolation and characterization of a cloned DNA sequence associated with the murine $A h$ locus and 3-methylcholanthrene-induced form of cytochrome P-450. Proc. Natl. Acad. Sci. USA 78:800-804.

11.Owczarek, C.M., P. Enriquez-Harris and N. Proudfoot. 1992. The primary transcription unit of the human $\alpha 2$ globin gene defined by quantitative RT/PCR. Nucleic Acids Res. 20:851-858

12.Reiners, J.J. Jr., A.R. Cantu, G. Thai and A. Schöller. 1992. Differential expression of basal and hydrocarbon-induced cytochrome P450 monooxygenase and quinone reductase activities in subpopulations of murine epidermal cells differing in their stages of differentiation. Drug Metabol. Dispos. 20:360-366.

13.Reiners, J.J. Jr., A. Schöller, P. Bischer, A.R. Cantu and A. Pavone. 1993. Suppression of cytochrome P450 Cypla-1 induction in murine hepatoma $1 \mathrm{c} 1 \mathrm{c} 7$ cells by $12-0-$ tetradecanoylphorbol-13-acetate and inhibitors of protein kinase C. Arch. Biochem. Biophys. 301:449-454.

14.Trapnell, B.C. 1993. Quantitative evaluation of gene expression in freshly isolated human respiratory epithelial cells. Am. J. Physiol. 264:L199-L212.

15.Vanden Heuvel, J.P., F.L. Tyson and D.A. Bell. 1993. Construction of recombinant RNA templates for use as internal standards in quantitative RT-PCR. BioTechniques 14:395398.

16.Vannice, J.L., J.M. Taylor and G.M. Ringold. 1984. Glucocorticoid-mediated induction of $\alpha_{1}$-acid glycoprotein: evidence for hormone-regulated RNA processing. Biochemistry 81:4241-4245.

17.Wang, A.M., M.V. Doyle and D.F. Mark. 1989. Quantitation of mRNA by the polymerase chain reaction. Proc. Natl. Acad. Sci.
USA 86:9717-9721.

18. Whitlock, J.P. Jr. 1987. The regulation of gene expression by 2,3,7,8-tetrachlorodibenzo-p-dioxin. Pharmacol. Rev. 39:147-161.

19.Yang, M. and M. Kurkinen. 1994. Different mechanisms of regulation of the human stromelysin and collagenase genes. Eur. J. Biochem. 222:651-658.

Received 7 June 1995; accepted 12 September 1995.

Address correspondence to:

Cornelis J. Elferink

Institute of Chemical Toxicology

Wayne State University

2727 Second Ave.

Room 4000

Detroit, MI 48201, USA

Internet:celferi@cms.cc.wayne.edu 